\title{
Neutrophil Accumulation on Activated, Surface-adherent Platelets in Flow Is Mediated by Interaction of Mac-1 with Fibrinogen Bound to $\alpha$ llb $\beta 3$ and Stimulated by Platelet-activating Factor
}

\author{
Christian Weber and Timothy A. Springer \\ The Center for Blood Research and Department of Pathology, Harvard Medical School, Boston, Massachusetts 02115
}

\begin{abstract}
We have studied the pathways that lead to arrest and firm adhesion of rolling PMN on activated, surface-adherent platelets. Stable arrest and adhesion strengthening of PMN on thrombin-stimulated, surface-adherent platelets in flow required distinct $\mathrm{Ca}^{2+}$ - and $\mathrm{Mg}^{2+}$-dependent regions of Mac-1 $(\alpha \mathrm{M} \beta 2)$, and involved interactions of Mac-1 with fibrinogen, which was bound to platelets via $\alpha \mathrm{IIb} \beta 3$. Mac-1 also bound to other unidentified ligands on platelets, which were not intracellular adhesion molecule-2 (ICAM-2), heparin, or heparan-sulfate proteoglycans. This was shown by inhibition with $\mathrm{mAbs}$ or peptides, by treatment of platelets with heparitinase, and by using platelets with defective $\alpha \operatorname{IIb} \beta 3$ from a patient with Glanzmann thrombasthenia. Tethering of PMN on platelet ICAM-2 via LFA-1 ( $\alpha$ L $\beta 2)$ was observed, which may facilitate the transition between rolling on selectins and Mac-1-dependent arrest. Arrest and adhesion strengthening was pertussis toxin sensitive and in flow was mainly induced by platelet-activating factor but not through activation of the chemokine receptor CXCR2. In stasis, spreading occurred and the CXCR2 contributed to firm adhesion. ( $J$. Clin. Invest. 1997. 100:2085-2093.) Key words: platelets • polymorphonuclear leukocytes - integrins - selectins • chemokines
\end{abstract}

\section{Introduction}

A multistep model with a sequential involvement of various traffic signal molecules has been proposed for transendothelial extravasation of leukocytes. Selectins initiate tethering and rolling of leukocytes and serve as a prerequisite for their stable arrest upon stimulation of $\beta 2$ integrins with chemoattractants in flow $(1,2)$. Platelets express P-selectin which is mobilized from $\alpha$-granules to the plasma membrane upon activation (3, 4 ), and constitutively express the $\beta 2$ integrin ligand ICAM-2

Address correspondence to Timothy A. Springer, The Center for Blood Research and Department of Pathology, Harvard Medical School, 200 Longwood Avenue, Boston, MA 02215. Phone: 617-2783200; FAX: 617-278-3232; E-mail: springer@sprsgi.med.harvard.edu

Received for publication 17 March 1997 and accepted in revised form 11 July 1997.

J. Clin. Invest.

(C) The American Society for Clinical Investigation, Inc. 0021-9738/97/10/2085/09 \$2.00

Volume 100, Number 8, October 1997, 2085-2093

http://www.jci.org (intercellular adhesion molecule-2) ${ }^{1}$ (5). Hence, the multistep model may also apply to the highly efficient accumulation of PMN on activated, surface-adherent platelets in flow. Indeed, rolling and arrest of PMN on activated platelets in flow requires the sequential action of $\mathrm{P}$-selectin and $\beta 2$ integrins, respectively, as demonstrated by inhibition of rolling with $\mathrm{mAb}$ to P-selectin and a lack of firm adhesion of PMN from patients with leukocyte adhesion deficiency-1 (6-10). Moreover, the dynamic interaction of activated platelets and PMN in stirred suspensions involves a P-selectin-dependent step and a functional signal that proceeds through tyrosine kinase activation to stimulate adhesiveness of Mac-1 (11). It has been shown that, in stasis, adhesion strengthening of PMN on thrombin-stimulated, surface-adherent platelets was mediated by binding of Mac-1 ( $\alpha \mathrm{M} \beta 2)$ on PMN to unidentified ligands on platelets, but does not require LFA-1 $(\alpha \mathrm{L} \beta 2)$ on PMN or ICAM- 2 on platelets (10). Fibrinogen, a Mac-1 ligand $(12,13)$ that can bind to activated platelets via $\alpha \operatorname{IIb} \beta 3$ (14), has been implicated in platelet-PMN interactions in cell suspension or whole blood (15). However, the role of Mac-1 in adherence of PMN in flow and the identity of the $\beta 2$ integrin ligands which mediate PMN arrest on activated platelets in flow remain to be elucidated.

The adhesiveness of $\beta 2$ integrins requires activation. Chemoattractants and CXC chemokines, such as IL-8, have been shown to stimulate the avidity of Mac-1 in PMN $(16,17)$ and convert selectin-mediated rolling of PMN into firm arrest (1). Interactions of PMN and platelets are required for the production of certain chemokines, and for transcellular leukotriene and arachidonic acid metabolism (18). Activated platelets produce chemoattractants, such as the lipid mediator platelet-activating factor (PAF), which could stimulate PMN integrins. Platelets also express the CXC chemokines ENA-78, GRO- $\alpha$, (19) and $\beta$-thromboglobulin (CTAP-III), a precursor for the CXC chemokine neutrophil-activating peptide-2 (NAP-2), which is released from platelet $\alpha$-granules and processed by the PMN enzyme cathepsin G (20-22). Unlike IL-8, which activates both CXCR1 and CXCR2, the CXC chemokines expressed by platelets act through the CXCR2 but not CXCR1 on PMN (23). The receptor for PAF and the CXCR2 differ in signal transduction and coupling to $\mathrm{G} \alpha$ proteins (24). Moreover, lipid mediators but not CXC chemokines are soluble in the plasma membrane, whereas chemokines but not lipid mediators bind to heparin or proteoglycans. This might lead to a differential role for these chemoattractants in activation of PMN in flow.

The exact mechanisms of PMN accumulation on thrombinstimulated platelets, in particular the involvement of Mac-1 on

1. Abbreviations used in this paper: ICAM-2, intracellular adhesion molecule-2; LTB4, leukotriene B4; PAF, platelet-activating factor; PTX, pertussis toxin. 
PMN and of $\beta 2$ integrin ligands on platelets, and the role of platelet chemoattractants in the activation of integrin-mediated arrest, remain to be characterized. Here we show that PMN accumulation in flow involves interactions of Mac- 1 with fibrinogen presented by $\alpha \operatorname{IIb} \beta 3$ on platelets, activation by $\mathrm{PAF}$, and possibly tethering on platelet ICAM-2.

\section{Methods}

Reagents and mAbs. The mAbs CBRM1/9, CBRM1/20, CBRM1/29 (25), LPM19c (kindly provided by Dr. K. Pulford, Oxford, United Kingdom) (26), OKM1 (27) to Mac-1 ( $\alpha$ M, CD11b), and CBR-IC2/2 (28) to ICAM-2 were purified with protein A. The mAb $10 \mathrm{H} 2$ to CXCR2 (29) was kindly provided by Dr. C. Hebert (Genentech, South San Francisco, CA). A blocking mAb to $\alpha \operatorname{IIb} \beta 3$ (7E3) was kindly provided by Dr. B.S. Coller (Mount Sinai Hospital, New York) (30). A blocking (PM6/13) and a nonblocking mAb to $\alpha \mathrm{IIb}$ (PM6/248) were from Biosource (Camarillo, CA). The F(ab')2 fragment of a goat polyclonal antiserum to fibrinogen (kindly provided by Dr. C. Alper, Center For Blood Research, Boston, MA) was prepared by pepsin treatment and protein A purification using an ImmunoPure kit (Pierce Chemical Co., Rockford, IL). Purity and binding capacity of $\mathrm{F}\left(\mathrm{ab}^{\prime}\right) 2$ was confirmed by reducing and nonreducing SDS/ PAGE with Coomassie staining and by flow cytometry with activated platelets, respectively. UK-74,505 (31) was a gift from Pfizer (Sandwich, United Kingdom); SC-23634 was a gift from Searle \& Co. (Skokie, IL). P1 peptide (KYGWTVFQKRLDGSV) was synthesized by Research Genetics. All other reagents were from Sigma Chemical Co. (St. Louis, MO).

Cells. Platelet-rich plasma was prepared by centrifugation of whole venous blood from healthy control donors and a patient with Glanzmann thrombasthenia (32). For anticoagulation, blood was diluted 9:1 in acid-citrate-dextrose $(85 \mathrm{mM}$ trisodium citrate, $69 \mathrm{mM}$ citric acid, $111 \mathrm{mM}$ glucose, $\mathrm{pH} 4.6$ ) with $50 \mathrm{ng} / \mathrm{ml} \mathrm{PGE}_{1}$. The diagnosis of Glanzmann thrombasthenia had been established clinically by chronic thrombocytopenic purpura and prolonged bleeding time, as well as biochemically and functionally, i.e., by severe decrease of $\alpha \operatorname{IIb} \beta 3$ as shown by SDS-PAGE of surface-labeled platelets, surface expression on platelets in flow cytometry, and abnormal platelet aggregation (32), while levels of $\alpha v \beta 3$ were normal (33). Platelets were washed and resuspended at $5 \times 10^{8} / \mathrm{ml}$ in a Hepes buffer $(145 \mathrm{mM} \mathrm{NaCl}, 10 \mathrm{mM}$ Hepes, $0.5 \mathrm{mM} \mathrm{Na}_{2} \mathrm{HPO}_{4}, 5 \mathrm{mM} \mathrm{KCl}, 2 \mathrm{mM} \mathrm{MgCl} 2,0.1 \%$ glucose, $\mathrm{pH}$ 7.4). Platelets were counted in a FACScan ${ }^{\circledR}$ (Becton Dickinson, Mountain View, CA), showing $<0.1 \%$ contamination with erythrocytes or leukocytes. Purified human platelets were bound to 3-aminopropyltriethoxysilane (APES)-treated glass slides $(5,7,10)$ for $30 \mathrm{~min}$, and nonspecific binding was blocked with $0.5 \%$ HSA in Hepes buffer for $30 \mathrm{~min}$ at $37^{\circ} \mathrm{C}$. A confluent layer of spread platelets was formed. The density and confluence of platelet layers was examined by light microscopy before and after each experiment and was not affected by preincubation conditions, by high shear in detachment assays, or by whether platelets were from healthy controls or from the patient with Glanzmann thrombasthenia. PMN were isolated from the same blood sample by dextran sedimentation, Ficoll-Hypaque density separation and hypotonic lysis $(34,35)$. PMN were resuspended in HBSS with $10 \mathrm{mM}$ Hepes ( $\mathrm{pH} 7.4$ ) and $0.2 \%$ HSA for $<4 \mathrm{~h}$. For flow assays, $1 \mathrm{mM}$ $\mathrm{MgCl}_{2} / 1 \mathrm{mM} \mathrm{CaCl} 2 ; 2 \mathrm{mM} \mathrm{CaCl}_{2} ;$ or $2 \mathrm{mM} \mathrm{MgCl} / 5 \mathrm{mM}$ EGTA were added.

Attachment and controlled detachment assays in flow. Adherent platelets on glass slides were activated with thrombin $(0.1 \mathrm{U} / \mathrm{ml})$ at $37^{\circ} \mathrm{C}$, assembled as the lower wall in a parallel flow chamber and mounted on an inverted phase-contrast microscope $(1,36)$. The platelet substrate was perfused with HBSS with $10 \mathrm{~mm}$ Hepes (pH 7.4) and $0.2 \%$ HSA before infusion of neutrophils. For accumulation and tethering, PMN $\left(10^{6} / \mathrm{ml}\right)$ were perfused through the chamber for $3 \mathrm{~min}$ at the appropriate flow rates to obtain the indicated shear stresses at the chamber wall (1). The number of firmly adherent cells (moving less than one cell diameter in the last $10 \mathrm{~s}$ of the 3 -min period) was counted after $3 \mathrm{~min}$. The number of tethered cells (bound $>3 \mathrm{~s}$ ) was counted over the same 3-min period. Cells were also allowed to settle in stasis and counted. After adherence in flow or stasis, the shear flow was incrementally increased every 10 -s up to $36 \mathrm{dyn} / \mathrm{cm}^{2}$ and cells remaining adherent at the end of each $10 \mathrm{~s}$ interval, and cells rolling (moving more than one cell diameter) within the 10-s intervals were counted. Data are expressed as percentage of initially bound cells remaining adherent, and as percentage of cells in the field rolling. Bound cells were released with HBSS $/ 5 \mathrm{mM}$ EDTA at $30 \mathrm{dyn} / \mathrm{cm}^{2}$. For inhibition experiments, PMN were pretreated for $15 \mathrm{~min}$ with $\mathrm{mAb}(20 \mu \mathrm{g} / \mathrm{ml})$, antagonists $(10 \mu \mathrm{M})$, or peptides $(100 \mu \mathrm{M})$, which were kept present during assays, or for $2 \mathrm{~h}$ with pertussis toxin (PTX, $50 \mathrm{ng} / \mathrm{ml})$ at $25^{\circ} \mathrm{C}$. Surface-adherent platelets were preincubated with $\mathrm{mAb}$ or $\mathrm{F}\left(\mathrm{ab}^{\prime}\right) 2(20 \mu \mathrm{g} / \mathrm{ml})$, heparin $(500 \mu \mathrm{g} / \mathrm{ml})$, or peptides $(100 \mu \mathrm{M})$ for 15 min during activation with thrombin. All experiments included isotype-matched $\mathrm{IgG}$ as a negative control. Platelet layers were also pretreated with heparitinase $(0.5 \mathrm{U} / \mathrm{ml})$ in $\mathrm{HBSS} / \mathrm{Hepes}$ with $2 \mathrm{mM}$ $\mathrm{CaCl}_{2}$ for $1 \mathrm{~h}$ at $25^{\circ} \mathrm{C}$, and washed. To confirm that heparitinase was effective, soluble heparan sulfate was included in control treatments of platelet substrates, recovered and analyzed by spectrophotometrical assay of its cleavage product uronic acid (37), and by changes in electrophoretic mobility in SDS/PAGE with toluidin blue staining (38) (not shown). Data were expressed as mean $\pm \mathrm{SD}$, and were statistically analyzed by ANOVA or Student's $t$ test using Bonferroni corrections, where appropriate.

\section{Results}

Consistent with previous studies (6-10), the initial interaction and rolling of PMN on activated platelets was mediated by P-selectin (not shown), however few continuously rolling PMN were seen, since rolling was immediately followed by highly efficient arrest. We studied the role of Mac-1 $(\alpha \mathrm{M} \beta 2)$ in the rapid arrest and accumulation of PMN on thrombin-stimulated, surface-adherent platelets in flow, and in particular the contribution of specific regions of Mac-1 by using mAbs which bind to different epitopes of $\alpha \mathrm{M}$. We found that the accumulation of PMN on activated platelets at a shear of $1.5 \mathrm{dyn} / \mathrm{cm}^{2}$ over 3 min was hardly affected by CBRM1/29, an mAb to the I or inserted domain of $\alpha \mathrm{M}$; however, it was significantly inhibited by LPM19c, another mAb mapping to the I domain, by CBRM1/20, an mAb to the divalent cation repeats, and by OKM1, an mAb to the COOH terminus (Fig. $1 A$ ). CBRM1/9, an $\mathrm{mAb}$ to the $\mathrm{COOH}$ terminus of $\alpha \mathrm{M}$, and $\mathrm{TS} 1 / 22$, an $\mathrm{mAb}$ to $\alpha \mathrm{L}$, had no effect (Fig. $1 A$ and not shown). Accumulation of $\mathrm{PMN}$ was also inhibited by the presence of $\mathrm{P} 1$ peptide (39) which contains the $\gamma$-chain motif (190-202) in fibrinogen that interacts with Mac-1 (Fig. $1 A$ ). Accumulation was not significantly inhibited with $\mathrm{H} 12$ or RGDS peptides which represent distinct binding sites in fibrinogen for $\alpha \operatorname{IIb} \beta 3(40,41)$ (Fig. $1 A$ ). The pattern of inhibition by Mac- $1 \mathrm{mAbs}$ of accumulation in flow in $\mathrm{Mg}^{2+}$ and $\mathrm{Ca}^{2+}$ differed from adhesion in stasis, which is inhibited by CBRM1/29 mAb in the presence of $\mathrm{Mg}^{2+} / \mathrm{EGTA}(10)$.

To investigate adhesion strengthening of PMN after arrest on platelets in flow, we used controlled detachment assays. In contrast to its marginal effect on accumulation, the I domain $\mathrm{mAb}$ CBRM1/29 reduced by up to $50 \%$ the resistance of PMN to detachment by increments in wall shear stress, and increased the percentage of PMN rolling on activated platelets more than twofold (Fig. 1, $B$ and $C$ ). Similarly, the I domain mAb LPM19c potently reduced shear resistance and increased rolling of PMN (Fig. 1, $B$ and $C$ ). The mAbs OKM1, CBRM1/20, or $\mathrm{P} 1$ peptide, which inhibited accumulation, did not affect shear 


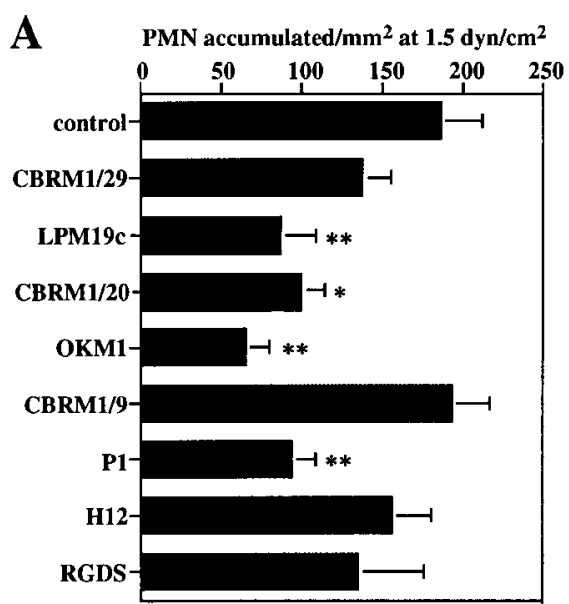

P1 = KYGWTVFQKRLDGSV H12 = HHLGGAKQAAGDV
B
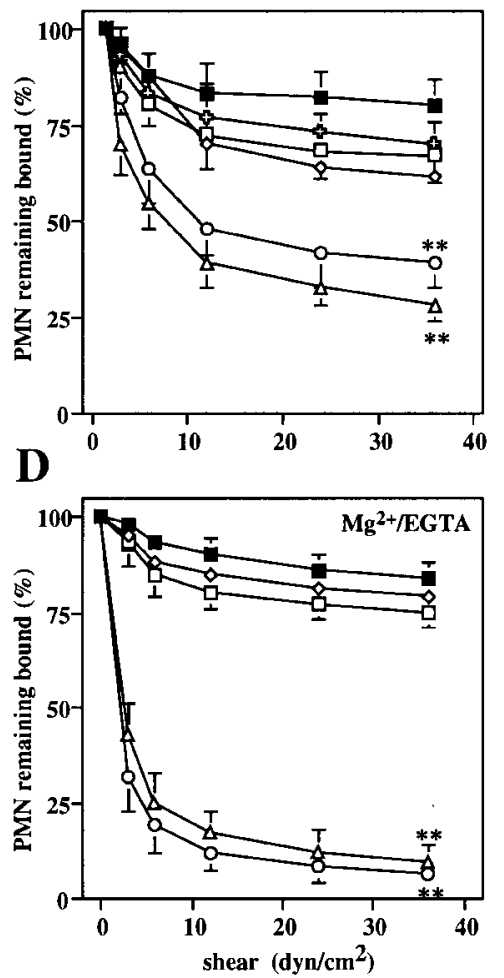

C
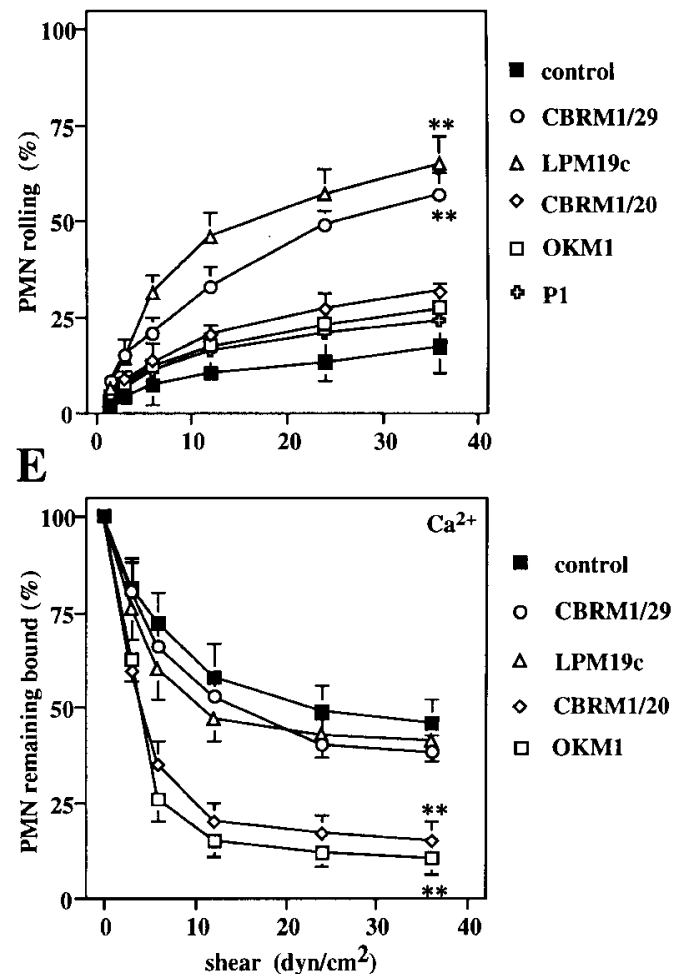

Figure 1. Role of Mac-1 in attachment and adhesion strengthening of PMN on activated, surface-adherent platelets in flow. PMN were pretreated with mAbs to distinct epitopes of Mac-1 (CBRM1/29, LPM19c, CBRM1/20, CBRM1/9) or with peptides corresponding to fibrinogen binding sites for Mac-1 $(P 1)$ or $\alpha \operatorname{IIb} \beta 3(H 12, R G D)$. (A) Accumulation of PMN on thrombin-stimulated platelets for $3 \mathrm{~min}$ at $1.5 \mathrm{dyn} / \mathrm{cm}^{2}$. $\left(B\right.$ and $C$ ) Controlled detachment assays with PMN after attachment in flow for 3 min at $1.5 \mathrm{dyn} / \mathrm{cm}^{2}$. Shear flow was increased every $10 \mathrm{~s}$, and the percentage of PMN remaining attached $(B)$ or rolling $(C)$ was determined. $(D$ and $E$ ) Controlled detachment assays after attachment in stasis for $5 \mathrm{~min}$ in the presence of $2 \mathrm{mM} \mathrm{Mg}{ }^{2+} / 5 \mathrm{mM}$ EGTA $(D)$ or $2 \mathrm{mM} \mathrm{Ca}^{2+}(E)$. Shear flow was increased every $10 \mathrm{~s}$ and the percentage of $\mathrm{PMN}$ remaining attached was determined. Data are mean \pm SD of three independent experiments. $* P<0.05 ; * * P<0.01$.

resistance or rolling (Fig. $1, B$ and $C$ ). The mAb CBRM1/9 (Fig. 1, $A$ and $C$ ) or the $\alpha \mathrm{L}$ mAb TS1/22 (not shown) affected neither accumulation nor shear resistance.

The functions of distinct regions targeted by $\alpha \mathrm{M}$ mAbs, e.g., I domain vs. divalent cation repeats present in the putative $\beta$ propeller domain (42), may involve different divalent cations. Adhesion in shear flow requires $\mathrm{Ca}^{2+}$-dependent interactions through $\mathrm{P}$-selectin; therefore, to analyze the dependence of the Mac-1 functions inhibited by these mAbs on divalent cations, we studied adhesion developed for 5 min in stasis in the presence of different divalent cations. All mAbs were able to bind to $\alpha \mathrm{M}$ in the absence of $\mathrm{Ca}^{2+}$ or $\mathrm{Mg}^{2+}$, except CBRM1/20, which did not bind in the absence of $\mathrm{Ca}^{2+}$ (data not shown). In the absence of $\mathrm{Ca}^{2+}$ and in the presence of $\mathrm{Mg}^{2+}$, i.e., in $\mathrm{Mg}^{2+} / \mathrm{EGTA}$, resistance to increased shear was inhibited by the mAbs LPM19c and CBRM1/29 but not by the mAbs OKM1 or CBRM1/20 (Fig. $1 D$ ). In contrast, in the absence of $\mathrm{Mg}^{2+}$ and in the presence of $\mathrm{Ca}^{2+}$, shear resistance of PMN adhesion was impaired by $\sim 50 \%$, and was markedly inhibited by the mAbs OKM1 and CBRM1/20 but not by the mAbs LPM19c and CBRM1/29 (Fig. $1 E$ ). The I domain mAbs CBRM1/4, CBRM1/31, and CBRM1/34 showed inhibitory effects on PMN accumulation and $\mathrm{Mg}^{2+}$-dependent firm adhesion, comparable to the effects of the mAbs LPM19c or CBRM1/29 (data not shown).

We next explored the involvement of fibrinogen which interacts with activated $\alpha \operatorname{IIb} \beta 3$ on platelets. Platelet substrates were pretreated with inhibitors, which remained present during thrombin treatment, and were washed out before infusion of neutrophils. Pretreatment of platelets with an antifibrinogen $\mathrm{F}\left(\mathrm{ab}^{\prime}\right) 2$ inhibited arrest of PMN by $>50 \%$ (Fig. $2 A$ ), whereas antifibrinogen $\operatorname{IgG}$ was less effective (not shown), probably due to Fc receptor interactions. Fibrinogen binding to activated platelets can be blocked by the mAb 7E3 to platelet $\alpha \mathrm{IIb} \beta 3, \mathrm{H} 12$ peptide containing the fibrinogen $\gamma$-chain binding site for $\alpha \mathrm{IIb} \beta 3$, and RGDS which inhibits binding of $\alpha \operatorname{IIb} \beta 3$ to the fibrinogen $A \alpha$ chain $(30,40,41)$. Accumulation of $\mathrm{PMN}$ was reduced by pretreatment of platelet substrates with 7E3 mAb, or H12 peptide and RGDS peptide (Fig. $2 A$ ). H12 was more potent than RGDS, and combining both had additive effects (Fig. 2 A). Moreover, PM6/13, a blocking mAb to $\alpha \mathrm{II} \beta$, inhibited PMN arrest (data not shown), whereas pretreatment of platelets with PM6/248, a nonblocking $\mathrm{mAb}$ to $\alpha \mathrm{IIb}$, or with P1 peptide had no effect (Fig. $2 A$ ). The mAb 7E3 also reacts with $\alpha \mathrm{v} \beta 3$ (43), and with Mac-1 only when activated with ADP (44). Removal of unbound 7E3 mAb by washing af- 


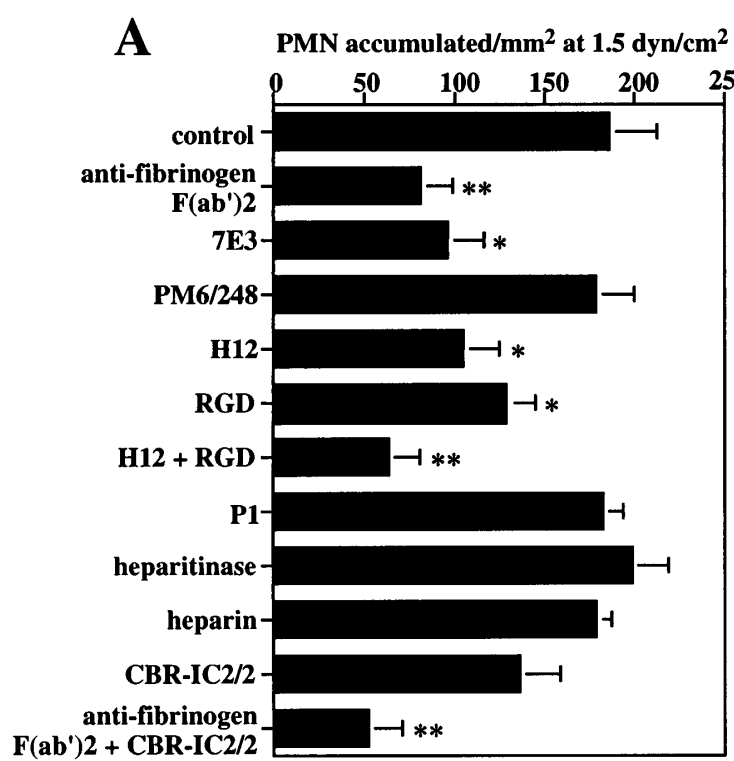

B

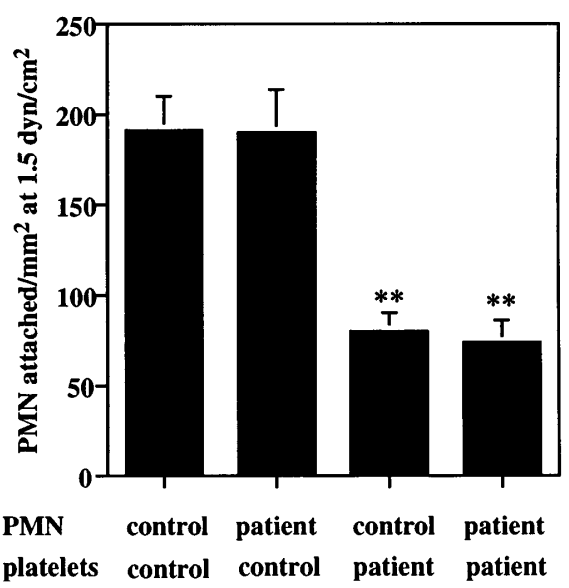

$\mathbf{F}\left(\mathbf{a b}^{\prime}\right) 2+\mathrm{CBR}-\mathrm{IC} 2 / 2 \longrightarrow-1 * *$

C

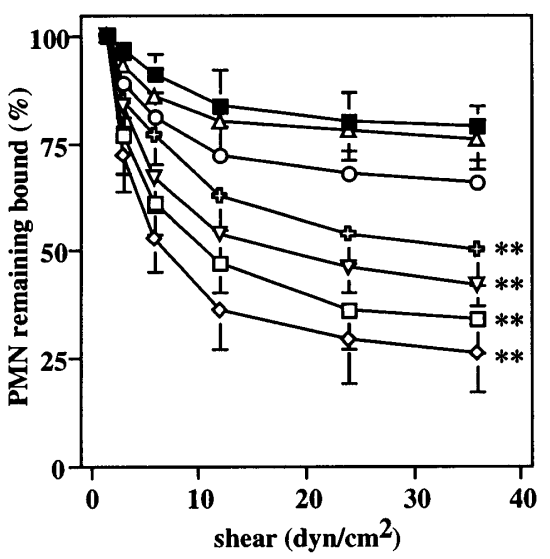

D

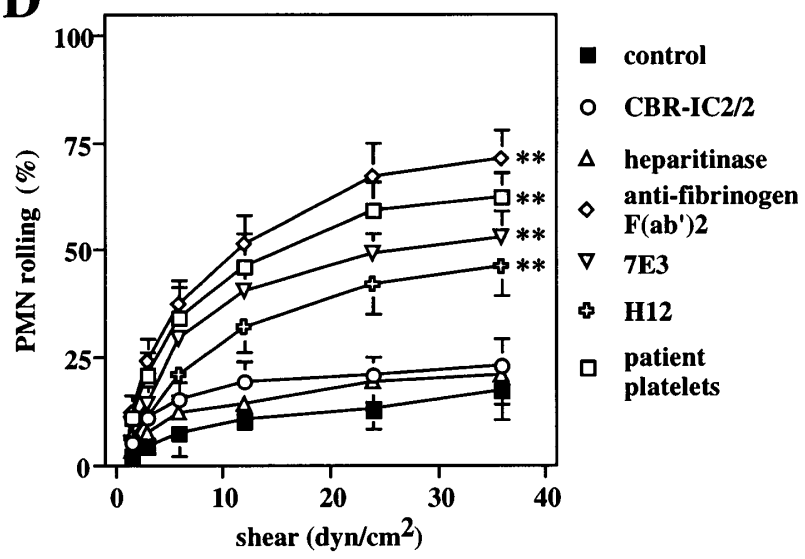

Figure 2. Involvement of platelet ligands in attachment and adhesion strengthening of PMN on activated, surface-adherent platelets in flow. $(A-C)$ Thrombin-stimulated platelets were pretreated with antifibrinogen $\mathrm{F}\left(\mathrm{ab}^{\prime}\right) 2$, mAb to ICAM-2 (CBR-IC2/2), $\mathrm{mAbs}$ to $\alpha \operatorname{IIb} \beta 3$ (blocking $7 E 3$, nonblocking PM6/248), heparin $(500 \mu \mathrm{g} / \mathrm{ml})$, peptides P1, H12, or RGD, or heparitinase. (A) Accumulation of PMN on thrombin-stimulated platelets for $3 \mathrm{~min}$ at $1.5 \mathrm{dyn} / \mathrm{cm}^{2}$. (B) Accumulation on thrombin-stimulated platelets for 3 min comparing cells isolated from healthy donors with cells from a patient with Glanzmann's thrombasthenia. $(C$ and $D)$ Controlled detachment assays after attachment in flow for 3 min. Shear flow was increased every $10 \mathrm{~s}$, and the percentage of PMN remaining attached $(C)$ or rolling $(D)$ was determined. $* P<0.05$, ** $P<0.01$.

ter platelet preincubation did not affect the inhibition of PMN arrest, indicating that it was not due to blocking activated Mac-1 on PMN. Moreover, the $\alpha \mathrm{IIb} \mathrm{mAb}$ PM6/13, not known to cross-react with $\alpha \mathrm{v} \beta 3$ or Mac-1, and peptides specific for binding sites of $\alpha \mathrm{IIb} \beta 3$ in fibrinogen, inhibited PMN arrest to a similar extent.

The platelet disorder Glanzmann thrombasthenia is characterized by genetic defects in $\alpha \mathrm{IIb} \beta 3$, which render the molecule nonfunctional or severely impairs its surface expression (45). Using activated, surface-adherent platelets from a patient with Glanzmann thrombasthenia, we found a significant but not complete reduction in attachment of PMN compared with platelets derived from healthy controls (Fig. $2 \mathrm{~B}$ ). This was seen with PMN from either patients or healthy controls. The inhibition and patient data showed that fibrinogen bound to $\alpha \mathrm{IIb} \beta 3$ was a major Mac-1 ligand involved in PMN arrest on activated platelets.
Since heparin has recently been demonstrated to be a ligand for Mac-1 (46), Mac-1 may also interact with heparan sulfate proteoglycans on platelets. However, pretreatment of platelets with heparitinase or the presence of heparin at concentrations sufficient to inhibit binding of Mac-1 (46) did not affect accumulation of PMN (Fig. $2 A$ ). Thus, it appears that binding of Mac-1 to heparan sulfate proteoglycans was not involved in the arrest of PMN on platelets. Interestingly, pretreatment of platelets with CBR-IC2/2, an mAb to the LFA-1 ligand ICAM-2, appeared to attenuate accumulation of PMN, alone or in combination with anti-fibrinogen $\mathrm{F}\left(\mathrm{ab}^{\prime}\right) 2$ (Fig. $2 A$ ). Although this effect was not marked enough to reach statistical significance, it may be consistent with a minor role of ICAM-2 in PMN arrest on activated platelets.

Similar effects were seen for adhesion strengthening after attachment in flow. Antifibrinogen $\mathrm{F}\left(\mathrm{ab}^{\prime}\right) 2, \alpha \mathrm{IIb} \beta 3 \mathrm{mAb} 7 \mathrm{E} 3$, $\alpha I I \beta$ mAb PM6/13, or H12 peptide, but not ICAM-2 mAb, hep- 
aritinase, heparin, or $\mathrm{P} 1$ peptide reduced the shear resistance of PMN adhesion by up to $50 \%$ and increased the percentage of PMN rolling on platelets (Fig. 2, $C$ and $D$ not shown). Consistently, shear resistance of PMN was markedly reduced on platelets from a patient with Glanzmann thrombasthenia, while rolling was increased (Fig. 2, $C$ and $D$ ).

ICAM-2 appeared to participate in PMN accumulation (Fig. $2 A$ ) but not in development of firm adhesion (Fig. 2, $C$ and $D$ ). To test for involvement of ICAM-2 in tethering, we examined interactions in shear flow in the absence of $\mathrm{Ca}^{2+}$ to exclude the contribution of selectins. At low shear flow, we observed tethering but not rolling of PMN on activated platelets that was $\mathrm{Mg}^{2+}$ dependent (Fig. $3 \mathrm{~A}$ ). Tethers were defined as adhesive interactions that lasted $>3 \mathrm{~s}$; almost all tethers were transient, i.e., there was little PMN accumulation. No interactions were seen when EDTA was added to remove cations (Fig. 3 A). Preincubation of platelets with the ICAM-2 mAb CBR-IC2/2 inhibited tethering at $0.75 \mathrm{dyn} / \mathrm{cm}^{2}$, showing that this interaction was mediated by ICAM-2 on platelets (Fig. $3 B$ ). Significant inhibition of tethering with an $\alpha \mathrm{L} \mathrm{mAb}$ (TS1/22) but not with an $\alpha \mathrm{M}$ mAb (LPM19c) indicated that it was mediated by the ICAM-2 counterreceptor LFA-1 with little or no contribution of Mac-1 on PMN (Fig. 3 B). Consistently, we also found LFA-1-dependent tethering on purified ICAM- 2 of PMN and K562 cells transfected with LFA-1 but not Mac-1 (not shown). Tethering on ICAM-2 may facilitate the transition between rolling on P-selectin and arrest via Mac-1.

Chemoattractants and chemokines are known to stimulate the avidity of Mac-1 in PMN $(16,17)$ and convert selectin-mediated rolling into firm arrest (1). Hence, we studied the role of chemoattractants in PMN accumulation and adhesion strengthening on activated platelets in flow. Pretreatment of PMN with the PAF receptor antagonist UK-74,505 (31) resulted in a significant and dose-dependent $(50 \%$ at $10 \mu \mathrm{M})$ inhibition of PMN accumulation (Fig. $4 A$, not shown). The leukotriene B4 (LTB4) receptor antagonist SC-53228 was less potent, and no additive effects were seen with both antagonists over UK-74,505 alone (Fig. $4 A$ ). Likewise, PTX $(50 \mathrm{ng} / \mathrm{ml})$ inhibited accumulation by $\sim 50 \%$ and showed little additive effect with UK-74,505. In contrast, pretreatment with CXCR2 mAb $10 \mathrm{H} 2$ did not inhibit arrest (Fig. $4 A$ ). Similar effects were seen for adhesion strengthening. UK-74,505, SC-53228, and PTX but not CXCR2 mAb reduced the shear resistance of PMN adhesion by up to $50 \%$, and increased the percentage of rolling PMN greater than twofold (Fig. 4, $B$ and $C$ ). Contrasting effects were obtained for adhesion to activated platelets in stasis. In this case, CXCR2 $\mathrm{mAb} 10 \mathrm{H} 2$, as well as UK-74,505 reduced shear resistance (Fig. 4 D). Moreover, CXCR2 mAb inhibited spreading of PMN on activated platelets, which occurs in stasis but not in flow (data not shown). These data demonstrated that CXCR2 $\mathrm{mAb}$ had inhibitory effects in stasis but not in flow. Thus, PMN arrest and adhesion strengthening on activated platelets in flow appeared to be stimulated by PAF and, to a lesser extent, by LTB4 through PTX-sensitive signaling pathways, but not via activation of CXCR2.

\section{Discussion}

Rolling and arrest of PMN on activated platelets in flow has been shown to require the sequential action of P-selectin and $\beta 2$ integrins, respectively (6-10). We confirmed the importance of P-selectin-mediated rolling as a prerequisite for firm

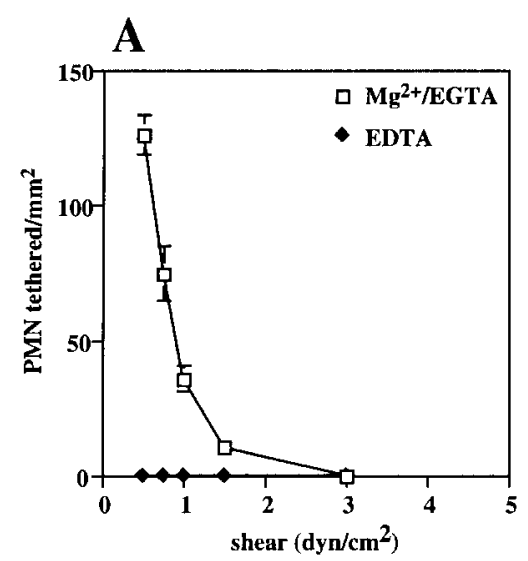

Figure 3. Selectin-independent tethering of PMN on activated, surface-adherent platelets in flow is mediated by LFA-1 on PMN and ICAM-2 on platelets. (A) Tethering of PMN on activated platelets. PMN were allowed to tether for 3 min at the indicated shear flow in the presence of $2 \mathrm{mM}$ $\mathrm{Mg}^{2+} / 5$ mM EGTA or 1 mM EDTA. (B) Inhibition with $\mathrm{mAb}$ of selectin-independent tethering of PMN on activated platelets. Platelets were pretreated with $\mathrm{mAbs}$ to ICAM-2 (CBR-IC2/2). PMN were pretreated with mAbs to LFA-1 (TS1/ 22), Mac-1 (LPM19c), or isotype control $\mathrm{mAb}$, and allowed to tether for $3 \mathrm{~min}$ at 0.75 dyn $/ \mathrm{cm}^{2}$ in $2 \mathrm{mM} \mathrm{Mg}^{2+} / 5$ mM EGTA. Data are mean \pm SD of three independent experiments. $* * P<0.01$.

attachment. The interaction of activated platelets and PMN in stirred suspension also involves a P-selectin-dependent step and a functional signal that stimulates Mac-1 adhesiveness through tyrosine kinase activation (11). Hence, it has been intriguing to apply a multistep model to the highly efficient accumulation of PMN on activated, surface-adherent platelets in flow. To further define elements of a sequential model, we examined the role of Mac- 1 on PMN and of $\beta 2$ integrin ligands and chemoattractants on platelets. Here we show that PMN accumulation in flow involves LFA-1-mediated transient interactions with platelet ICAM-2, the activation of integrin-mediated arrest by PAF, the presentation of fibrinogen by $\alpha \mathrm{IIb} \beta 3$ on platelets as a ligand for Mac-1, and distinct regions of Mac-1 to mediate firm attachment. Rolling on activated platelets was rapidly followed by Mac-1 mediated arrest on fibrinogen.

Our data suggest that distinct functional regions of Mac-1 contribute to PMN arrest and adhesion strengthening on activated platelets in flow. The seven $\mathrm{NH}_{2}$-terminal repeats of integrin $\alpha$ subunits have been predicted to fold into a $\beta$ propeller structure and to contain putative $\mathrm{Ca}^{2+}$-binding motifs located on the lower face (42). The I or inserted domain is predicted to be tethered to the top of the $\beta$ propeller structure and has a $\mathrm{Mg}^{2+}$ at its binding site. PMN accumulation on activated platelets in flow was inhibited by the mAb CBRM1/20 to the divalent cation repeats in the $\beta$ propeller domain of $\alpha \mathrm{M}$ and by $\mathrm{mAb}$ OKM1 to a region COOH-terminal to this domain. These $\mathrm{mAbs}$ also reduced shear resistance of PMN developed in stasis on activated platelets in the presence of $\mathrm{Ca}^{2+}$ and absence of $\mathrm{Mg}^{2+}$. Thus, the arrest of PMN may involve $\mathrm{Ca}^{2+}$-dependent 


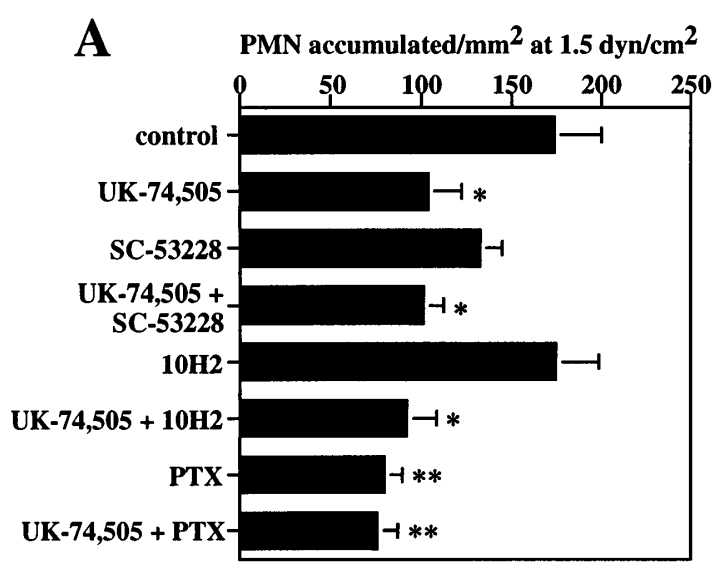

C

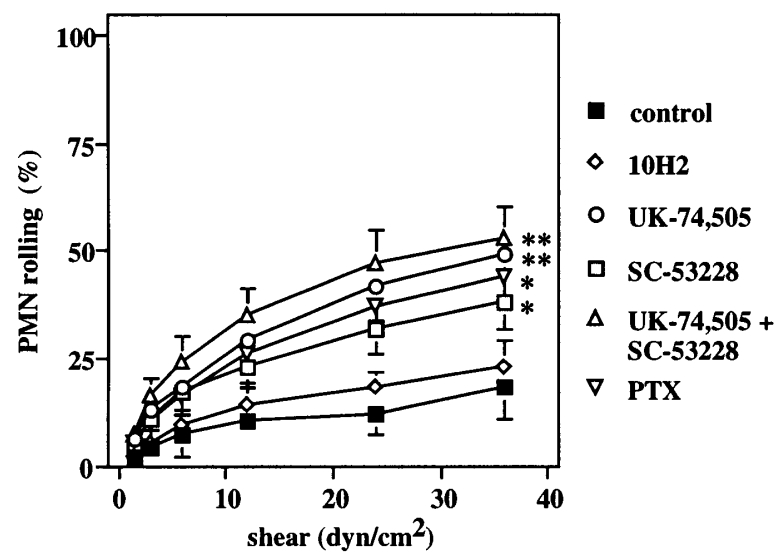

B

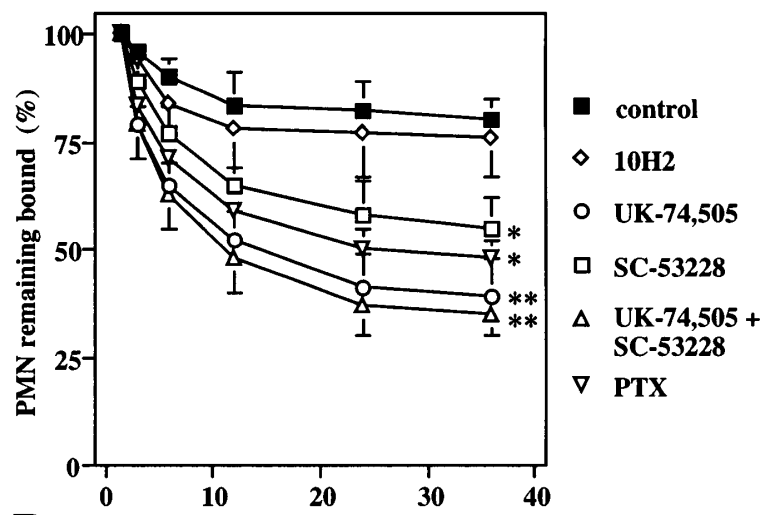

D

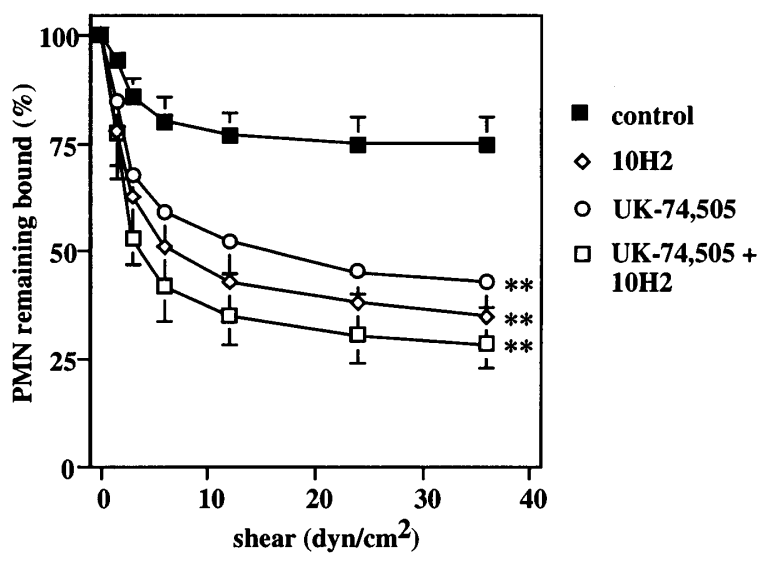

Figure 4. Role of chemoattractants in attachment and adhesion strengthening of PMN on activated, surface-adherent platelets in flow. PMN were pretreated with the PAF antagonist UK-74,505, the LTB4 antagonist SC-53228, the CXCR2 mAb 10H2, or with pertussis toxin $(P T X)$. $(A)$ Accumulation of PMN on thrombin-stimulated platelets for 3 min. $(B-D)$ Controlled detachment assays after attachment in flow for 3 min $(B$ and $C$ ) or in stasis for $5 \mathrm{~min}(D)$. Shear flow was increased every $10 \mathrm{~s}$, and the percentage of PMN remaining attached $(B$ and $D)$ or rolling $(C)$ was determined. Data are mean $\pm \mathrm{SD}$ of three independent experiments. $* P<0.05, * * P<0.01$.

regions of Mac-1. The inhibition of $\mathrm{PMN}$ accumulation with CBRM1/20 mAb to the putative $\beta$ propeller domain indicates that this region may contribute to PMN arrest on activated platelets. $\mathrm{Ca}^{2+}$ may stabilize the conformation of such a region rather than directly participate in binding. OKM1 mAb has been suggested to interfere with binding to fibrinogen by sterically affecting the I domain configuration or by blocking additional recognition sequences $(39,47)$. Accumulation of PMN in shear flow was also inhibited by some mAbs to the I domain of $\alpha M$, such as LPM19c but not by others, such as CBRM1/29. This suggests that the I domain may also be involved in PMN arrest on platelets. The apparently distinct properties of the I domain mAbs may be due to differences in their efficacy or in their binding sites on the I domain.

In contrast, shear resistance of PMN developed after adherence in flow was inhibited by both CBRM1/29, LPM19c, and other mAbs to the I domain, but not by OKM1 or CBRM1/20 mAb. Adhesion strengthening in stasis was dependent primarily on $\mathrm{Mg}^{2+}$, since it was reduced in the absence of $\mathrm{Mg}^{2+}$. In $\mathrm{Mg}^{2+} /$ EGTA but not in the absence of $\mathrm{Mg}^{2+}, \mathrm{mAbs}$ to the I domain but not OKM1 or CBRM1/20 inhibited adhesion strengthening in stasis. The lack of inhibition by CBRM1/
20 may be due to the $\mathrm{Ca}^{2+}$ dependency of its binding to $\alpha \mathrm{M}$; however, OKM1 mAb behaved similarly to CBRM1/20 mAb and is not $\mathrm{Ca}^{2+}$ dependent. Results with CBRM1/29 mAb are consistent with previous findings that it inhibits adhesion strengthening in stasis in $\mathrm{Mg}^{2+} /$ EGTA (10). Hence, adhesion strengthening involves $\mathrm{Mg}^{2+}$-dependent regions inhibited by $\mathrm{mAbs}$ to the I domain. Taken together, Mac-1 may be functionally subdivided into regions which contribute to initial arrest and regions which are required for subsequent adhesion strengthening in flow. Table I summarizes the relation of the $\mathrm{mAb}$ epitopes, their effects on accumulation, and adhesion strengthening and their cation dependency. Our data extend previous findings that $\mathrm{mAb}$ to different epitopes on Mac-1 can differentially inhibit adherence-dependent granulocyte functions, such as aggregation, directed migration in subagarose, binding to $\mathrm{iC} 3 \mathrm{~b}$, and complement-dependent phagocytosis (48-50).

Our data further indicate that arrest and adhesion strengthening of PMN on activated, surface-adherent platelets in flow is largely mediated by fibrinogen which is presented to Mac-1 on PMN by platelet $\alpha \operatorname{IIb} \beta 3$. Inhibition of PMN arrest with antifibrinogen $\mathrm{F}\left(\mathrm{ab}^{\prime}\right) 2$ and $\mathrm{P} 1$ peptide suggested that arrest in 
Table I. Effects of $m A b$ to Distinct $\alpha M$ Epitopes on Accumulation and Cation-dependent Adhesion Strengthening of PMN on Surface-adherent Platelets

\begin{tabular}{|c|c|c|c|c|c|}
\hline \multirow[b]{2}{*}{$\alpha \mathrm{M} \mathrm{mAb}$} & \multirow[b]{2}{*}{ Epitope } & \multirow{2}{*}{$\frac{\text { Accumulation }}{\mathrm{Ca}^{2+} / \mathrm{Mg}^{2+}}$} & \multicolumn{3}{|c|}{ Adhesion strengthening } \\
\hline & & & $\mathrm{Ca}^{2+} / \mathrm{Mg}^{2+}$ & $\mathrm{Ca}^{2+}$ & $\mathrm{Mg}^{2+} /$ EGTA \\
\hline LPM19c & I domain & + & + & - & + \\
\hline CBRM1/29 & I domain & \pm & + & - & + \\
\hline CBRM1/20 & Cation repeats & + & - & + & - \\
\hline OKM1 & $\mathrm{COOH}$-terminal & + & - & + & - \\
\hline CBRM1/9 & $\mathrm{COOH}$-terminal & - & - & - & - \\
\hline
\end{tabular}

Effects on accumulation and adhesion strengthening of PMN on surfaceadherent platelets were measured in the presence of the indicated cations. $(+)$, inhibitory effect of $\mathrm{mAb} ;(-)$, no inhibitory effect of $\mathrm{mAb}$.

flow involved interactions of Mac-1 with the fibrinogen $\gamma$-chain. P1 peptide contains the $\gamma$-chain motif in fibrinogen that interacts with Mac-1, but does not affect binding of fibrinogen to activated platelets (39). The mAb 7E3 to $\alpha \mathrm{IIb} \beta 3$, and the $\mathrm{H} 12$ and RGD peptides which contain the fibrinogen $\gamma$-chain and $\alpha$-chain binding sites for $\alpha \operatorname{IIb} \beta 3$, respectively, have been shown to inhibit fibrinogen binding to activated platelets $(30,40,41)$. Inhibition of PMN arrest by pretreatment of platelets with 7E3 $\mathrm{mAb}$, and with $\mathrm{H} 12$ and RGDS peptides further revealed that PMN arrest required fibrinogen that was bound to $\alpha \operatorname{IIb} \beta 3$. Combining $\mathrm{H} 12$ and RGDS had additive effects, consistent with findings that their binding sites on $\alpha \mathrm{IIb} \beta 3$ are spatially distinct but mutually exclusive (41). In contrast, Mac-1 does not utilize RGD motifs to bind fibrinogen (12). The importance of $\alpha \operatorname{IIb} \beta 3$ was confirmed by the reduced PMN accumulation on platelets with defective $\alpha \operatorname{IIb} \beta 3$. Thus, previous findings that ligand bridging between fibrinogen-binding integrins represents a mechanism of homotypic or heterotypic cell-cell interactions (51) are extended by our data in a more physiological context. Although heparin has been demonstrated to be a ligand for Mac-1 (46), interactions with heparan sulfate proteoglycans on platelets were not involved.

Our results in flow expand on previous evidence demonstrating the involvement of fibrinogen and $\alpha \operatorname{IIb} \beta 3$ in the adhesion of activated platelets to leukocytes in stasis (52), and implicating fibrinogen in platelet-PMN interactions in cell suspension or whole blood (15). However, we did not observe a complete inhibition of PMN accumulation and adhesion strengthening in flow with antifibrinogen $\mathrm{F}\left(\mathrm{ab}^{\prime}\right) 2$ in combination with ICAM-2 mAb, peptides, or 7E3 mAb. Hence, additional, unidentified ligands may contribute to PMN arrest and adhesion strengthening on activated platelets. This would be consistent with findings that platelets and fibrin are cooperative substrates for PMN adhesion under flow conditions (53), and may also explain why interactions of the fibrinogen $\gamma$-chain and the Mac-1 region targeted by OKM1 mAb may not play a major role in transient adhesion of activated platelets to PMN in mixed suspension (11). Shear rates can be estimated in that system but shear forces acting on adhering cells are not exactly defined and may be relatively moderate. Hence these results may be consistent with our data that OKM1 $\mathrm{mAb}$ and $\mathrm{P} 1$ peptide inhibit arrest in flow but not adhesion strengthening.
mAb to ICAM-2 modestly reduced, by itself or in combination with fibrinogen $\mathrm{F}\left(\mathrm{ab}^{\prime}\right)$ 2, PMN accumulation but not adhesion strengthening on activated platelets. We found transient interactions of PMN with platelets that were ICAM-2 and LFA-1 dependent, and occurred at shear stresses of $\leq 1.5 \mathrm{dyn} /$ $\mathrm{cm}^{2}$, representing the lower range of shear stresses found physiologically. Binding of activated PMN to artificial bilayers containing ICAM-1 has previously been described only at lower shear of $\leq 0.36 \mathrm{dyn} / \mathrm{cm}^{2}$ (1). LFA-1-mediated tethering on platelet ICAM-2 may represent a physiologically relevant interaction of a $\beta 2$ integrin with an Ig family member in shear flow, and may facilitate the transition between rolling on P-selectin and arrest via Mac-1.

The arrest and adhesion strengthening on platelets in flow appeared to be mainly stimulated by PAF, and to a lesser extent by LTB4, through PTX-sensitive signaling pathways, but not via activation of CXCR2. There are several explanations that may account for differences in the effectiveness of platelet chemoattractants in the activation of PMN in flow. Firstly, lipid mediators but not $\mathrm{CXC}$ chemokines are soluble in the lipid membrane, whereas chemokines but not lipid mediators can be bound to proteoglycans. The differential binding of chemokines to proteoglycan subpopulations may determine the presence and distribution of chemokines in the cellular microenvironment (54). Thus, PAF may be retained in the platelet plasma membrane by partition, whereas relevant platelet CXC chemokines may not be bound to platelet proteoglycans, and may be washed away in flow. Moreover, PMN enzymes required for processing precursors released by platelets into active CXC chemokines (22) may not be immobilized and may be removed by flow. This would be consistent with the inhibition of adhesion strengthening by the CXCR $2 \mathrm{mAb}$ in stasis but not in flow, and with our findings that spreading occurs in stasis but not in flow and is inhibited by CXCR2. Alternatively, the PAF receptor may differ from CXCR2 in its PTXsensitive signal transduction pathways and coupling to $\mathrm{G} \alpha$ proteins (24), which may enable a more rapid activation of Mac-1 adhesiveness in flow. In parallel to our results, endothelial PAF has been implicated in juxtacrine stimulation of integrin function in PMN tethered through P-selectin on thrombinstimulated endothelium (55). Although P-selectin itself does not stimulate adhesion of PMN via $\beta 2$ integrins in flow (1), it may signal to activate PMN (56), or cooperate with chemoattractants to stimulate leukocytes (57).

The mechanisms of PMN accumulation on activated, surface-adherent platelets reported here contribute to a more elaborate definition of the multistep model, by demonstrating a differential involvement of Mac-1 and LFA-1, their ligands and of chemoattractants in sequential steps of this process. Interactions between platelets and leukocytes occur at sites of vascular damage, as in hemostasis. Platelets bind to prothrombotic endothelium and to the underlying basement membrane in vascular injury, occupying a position analogous to the endothelium. Binding of PMN to platelets in a thrombus may facilitate immigration into thrombosed areas, wound healing, tissue repair, or protection from infection, and may contribute to the maintenance of vascular integrity, as well as to its impairment in pathological states. Platelets and PMN do indeed colocalize at sites of hemorrhage, vascular grafts, atherosclerotic lesions, and myocardial infarction (58-61). Activation of PMN with platelet adhesion occurs after coronary angioplasty and has been associated with late clinical events (62). Understand- 
ing the mechanisms of PMN accumulation on platelets in flow may lead to clinical applications and interventions that influence the consequences of leukocyte-platelet interactions in vascular disease.

\section{Acknowledgments}

We thank Dr. K. Pulford, Dr. B.S. Coller and Dr. C. Hebert for valuable mAbs, and Dr. A.D. Michelson (University of Massachusetts Medical Center) for patient blood.

C.W. was supported by Deutsche Forschungsgemeinschaft (We1913/1). This work was supported by National Institutes of Health Grant HL-48675 to T.A. Springer.

\section{References}

1. Lawrence, M.B., and T.A. Springer. 1991. Leukocytes roll on a selectin at physiologic flow rates: distinction from and prerequisite for adhesion through integrins. Cell. 65:859-873.

2. Springer, T.A. 1994. Traffic signals for lymphocyte recirculation and leukocyte emigration: The multi-step paradigm. Cell. 76:301-314.

3. Stenberg, P.E., R.P. McEver, M.A. Shuman, Y.V. Jacques, and D.F. Bainton. 1985. A platelet alpha granule membrane protein (GMP-140) is expressed on the plasma membrane after activation. J. Cell Biol. 101:880-886.

4. Larsen, E., A. Celi, G.E. Gilbert, B.C. Furie, J.K. Erban, R. Bonfanti, D.D. Wagner, and B. Furie. 1989. PADGEM protein: a receptor that mediates the interaction of activated platelets with neutrophils and monocytes. Cell. 59: $305-312$.

5. Diacovo, T.G., A.R. de Fougerolles, D.F. Bainton, and T.A. Springer. 1994. A functional integrin ligand on the surface of platelets: intercellular adhesion molecule-2. J. Clin. Invest. 94:1243-1251.

6. Palabrica, T., R. Lobb, B.C. Furie, M. Aronivitz, C. Benjamin, Y.-M. Hsu, S. Sajer, and B. Furie. 1992. Leukocyte accumulation promoting fibrin deposition is mediated in vivo by P-selectin on adherent platelets. Nature (Lond.). 359:848-851.

7. Buttrum, S.M., R. Hatton, and G.B. Nash. 1993. Selectin-mediated rolling of neutrophils on immobilized platelets. Blood. 82:1165-1174.

8. Yeo, E.L., J.-A.I. Sheppard, and I.A. Feuerstein. 1994. Role of P-selectin and leukocyte activation in polymorphonuclear cell adhesion to surface adherent activated platelets under physiologic shear conditions (an injury vessel wall model). Blood. 83:2498-2507.

9. Lalor, P., and G.B. Nash. 1995. Adhesion of flowing leukocytes to immobilized platelets. Br. J. Haematol. 89:725-732.

10. Diacovo, T.G., S.J. Roth, J.M. Buccola, D.F. Bainton, and T.A. Springer. 1996. Neutrophil rolling, arrest, and transmigration across activated, surface-adherent platelets via sequential action of P-selectin and the $\beta_{2}$-integrin CD11b/CD18. Blood. 88:146-157.

11. Evangelista, V., S. Manarini, S. Rotondo, N. Martelli, R. Polischuk, J.L. McGregor, G. de Gaetano, and C. Cerletti. 1996. Platelet/polymorphonuclear leukocyte interaction in dynamic conditions: Evidence of adhesion cascade and cross talk between P-selectin and the $\beta 2$ integrin CD11b/CD18. Blood. 88: 4183-4194

12. Altieri, D.C., R. Bader, P.M. Mannucci, and T.S. Edgington. 1988. Oligospecificity of the cellular adhesion receptor Mac-1 encompasses an inducible recognition specificity for fibrinogen. J. Cell Biol. 107:1893-1900.

13. Wright, S.D., J.I. Weitz, A.D. Huang, S.M. Levin, S.C. Silverstein, and J.D. Loike. 1988. Complement receptor type three (CD11b/CD18) of human polymorphonuclear leukocytes recognizes fibrinogen. Proc. Natl. Acad. Sci. USA. 85:7734-7738.

14. Pytela, R., M.D. Pierschbacher, M.H. Ginsberg, E.F. Plow, and E. Ruoslahti. 1986. Platelet membrane glycoprotein IIb/IIIa: member of a family of Arg-Gly-Asp-specific adhesion receptors. Science (Wash. DC). 231:1559-1562.

15. Ruf, A., R.F. Schlenk, A. Maras, E. Morgenstern, and H. Patscheke. 1992. Contact-induced neutrophil activation by platelets in human cell suspensions and whole blood. Blood. 80:1238-1246.

16. Lo, S.K., P.A. Detmers, S.M. Levin, and S.D. Wright. 1989. Transient adhesion of neutrophils to endothelium. J. Exp. Med. 169:1779-1793.

17. Detmers, P.A., S.K. Lo, E. Olsen-Egbert, A. Walz, M. Baggiolini, and Z.A. Cohn. 1990. Neutrophil-activating protein 1/interleukin 8 stimulates the binding activity of the leukocyte adhesion receptor CD11b/CD18 on human neutrophils. J. Exp. Med. 171:1155-1162.

18. Marcus, A.J., L.B. Safier, H.L. Ullman, N. Islam, M.J. Broekman, J.R. Falck, S. Fischer, and C. von Schacky. 1988. Platelet-neutrophil interactions: (12S)-hydroxyeicosatetraen-1 20-dioic acid: a new eicosanoid synthesized by unstimulated neutrophils from (12-S)-20-dihydroxyeicosatetraenoic acid. J. Biol. Chem. 263:2223-2229.

19. Power, C.A., R.B. Furness, C. Brawand, and T.N.C. Wells. 1994. Clon- ing of a full-length cDNA encoding the neutrophil-activating peptide ENA-78 from human platelets. Gene. 151:333-334.

20. Walz, A., and M. Baggiolini. 1989. A novel cleavage product of betathromboglobulin formed in cultures of stimulated mononuclear cells activates human neutrophils. Biochem. Biophys. Res. Commun. 159:969-975.

21. Cohen, A.B., M.D. Stevens, E.J. Miller, M.A.L. Atkinson, and G. Mullenbach. 1992. Generation of the neutrophil-activating peptide-2 by cathepsin G and cathepsin G-treated human platelets. Am. J. Physiol. 263:L249-L256.

22. Brandt, E., J. Van Damme, and H.-D. Flad. 1991. Neutrophils can generate their activator neutrophil-activating peptide 2 by proteolytic cleavage of platelet-derived connective tissue-activating peptide III. Cytokine. 3:311-321.

23. Baggiolini, M., B. Dewald, and B. Moser. 1994. Interleukin-8 and related chemotactic cytokines-CXC and CC chemokines. Adv. Immunol. 55:97-179.

24. Amatruda, T.T., N.P. Gerard, C. Gerard, and M.I. Simon. 1993. Specific interactions of chemoattractant factor receptors with G-proteins. J. Biol. Chem. 268:10139-10144.

25. Diamond, M.S., J. Garcia-Aguilar, J.K. Bickford, A.L. Corbi, and T.A Springer. 1993. The I domain is a major recognition site on the leukocyte integrin Mac-1 (CD11b/CD18) for four distinct adhesion ligands. J. Cell Biol. 120: 1031-1043.

26. Uciechowski, P., and R.E. Schmidt. 1989. NK and non-lineage antigens-cluster report: CD11. In Leucocyte Typing IV: White Cell Differentiation Antigens. W. Knapp, editor. Oxford University Press, Oxford, United Kingdom. 543-551.

27. Talle, M.A., P.E. Rao, E. Westberg, N. Allegar, M. Makowski, R.S. Mittler, and G. Goldstein. 1983. Patterns of antigenic expression on human monocytes as defined by monoclonal antibodies. Cell. Immunol. 78:83-99.

28. de Fougerolles, A.R., S.A. Stacker, R. Schwarting, and T.A. Springer. 1991. Characterization of ICAM-2 and evidence for a third counter-receptor for LFA-1. J. Exp. Med. 174:253-267.

29. Chuntharapai, A., J. Lee, C.A. Hébert, and K.J. Kim. 1994. Monoclonal antibodies detect different distribution patterns of IL-8 receptor A and IL-8 re ceptor B on human peripheral blood leukocytes. J. Immunol. 153:5682-5688.

30. Coller, B.S. 1985. A new murine monoclonal antibody reports an activation-dependent change in the conformation and/or microenvironment of the platelet glycoprotein IIb/IIIa complex. J. Clin. Invest. 76:101-108.

31. Pons, F., A.G. Rossi, K.E. Norman, T.J. Williams, and S. Nourshargh 1993. Role of platelet-activating factor (PAF) in platelet accumulation in rabbit skin: effect of the novel long-acting PAF antagonist, UK-74,505. Br. J. Pharmacol. 109:234-242.

32. Michelson, A.D. 1987. Flow cytometric analysis of platelet surface glycoproteins: phenotypically distinct subpopulations of platelets in children with chronic myeloid leukemia. J. Lab. Clin. Med. 110:346-354.

33. Lawler, J., and R.O. Hynes. 1989. An integrin receptor on normal and thrombasthenic platelets that binds thrombospondin. Blood. 74:2022-2027.

34. English, D., and B.R. Anderson. 1974. Single-step separation of red blood cells, granulocytes and mononuclear leukocytes on discontinuous density gradients of ficoll-hypaque. J. Immunol. Methods. 5:249-252.

35. Miller, L.J., D.F. Bainton, N. Borregaard, and T.A. Springer. 1987. Stimulated mobilization of monocyte Mac-1 and p150,95 adhesion proteins from an intracellular vesicular compartment to the cell surface. J. Clin. Invest. 80:535-544.

36. Weber, C., R. Alon, B. Moser, and T.A. Springer. 1996. Sequential regulation of $\alpha 4 \beta 1$ and $\alpha 5 \beta 1$ integrin avidity by CC chemokines in monocytes: implications for transendothelial chemotaxis. J. Cell Biol. 134:1063-1073.

37. Hovingh, P., and A. Linker. 1974. The disaccharide repeating-units of heparan sulfate. Carbohydr. Res. 37:181-192.

38. Carney, S.L. 1986. Proteoglycan analysis. In Carbohydrate Analysis. M.F. Chaplin and J.F. Kennedy, editors. IRL Press, Oxford, United Kingdom. 97-141.

39. Altieri, D.C., J. Plescia, and E.F. Plow. 1993. The structural motif glycine 190-Valine 202 of the fibrinogen $\gamma$ chain interacts with CD11b/CD18 integrin $\left(\alpha_{M} \beta_{2}\right.$, Mac-1) and promotes leukocyte adhesion. J. Biol. Chem. 268:18471853.

40. Lam, S.C.-T., E.F. Plow, M.A. Smith, A. Andrieux, J.-J. Ryckwaert, G. Marguerie, and M.H. Ginsberg. 1987. Evidence that arginyl-glycyl-aspartate peptides and fibrinogen $\gamma$ chain peptides share a common binding site on platelets. J. Biol. Chem. 262:947-950.

41. Bennett, J.S., S.J. Shattil, J.W. Power, and T.K. Gartner. 1988. Interaction of fibrinogen with its platelet receptor (differential effects of alpha and beta chain fibrinogen peptides on the glycoproteins IIb-IIIa complex). J. Biol. Chem. 263:12948-12953.

42. Springer, T.A. 1997. Folding of the N-terminal, ligand-binding region of integrin $\alpha$-subunits into a $\beta$-propeller domain. Proc. Natl. Acad. Sci. USA. 94: $65-72$.

43. Coller, B.S., D.A. Cheresh, E. Asch, and U. Seligsohn. 1991. Platelet vitronectin receptor expression differentiates Iraqi-Jewish from Arab patients with Glanzmann's thrombasthenia in Israel. Blood. 77:75-83.

44. Altieri, D.C., and T.S. Edgington. 1988. A monoclonal antibody reacting with distinct adhesion molecules defines a transition in the functional state of the receptor CD11b/CD18 (Mac-1). J. Immunol. 141:2656-2660.

45. Newman, P.J., U. Seligsohn, S. Lyman, and B.S. Coller. 1991. The mo- 
lecular genetic basis of Glanzmann's thrombasthenia in the Iraqi-Jewish and Arab populations in Israel. Proc. Natl. Acad. Sci. USA. 88:3160-3164.

46. Diamond, M.S., R. Alon, C.A. Parkos, M.T. Quinn, and T.A. Springer. 1995. Heparin is an adhesive ligand for the leukocyte integrin Mac-1 (CD11b/ CD18). J. Cell Biol. 130:1473-1482.

47. Zhou, L., D.H.S. Lee, J. Plescia, C.Y. Lau, and D.C. Altieri. 1994. Differential ligand binding specificities of recombinant CD11b/CD18 integrin I-domain. J. Biol. Chem. 269:17075-17079.

48. Ross, G.D., J.A. Cain, and P.J. Lachmann. 1985. Membrane complement receptor type three (CR3) has lectin-like properties analogous to bovine conglutinin and functions as a receptor for zymosan and rabbit erythrocytes as well as a receptor for iC3b. J. Immunol. 134:3307-3315.

49. Anderson, D.C., L.J. Miller, F.C. Schmalstieg, R. Rothlein, and T.A. Springer. 1986. Contributions of the Mac-1 glycoprotein family to adherencedependent granulocyte functions: structure-function assessments employing subunit-specific monoclonal antibodies. J. Immunol. 137:15-27.

50. Dana, N., B. Styrt, J. Griffin, R.F. Todd, III, M. Klempner, and M.A. Arnaout. 1986. Two functional domains in the phagocyte membrane glycoprotein Mo1 identified with monoclonal antibodies. J. Immunol. 137:3259-3263.

51. Gawaz, M.P., J.C. Loftus, M.L. Bajt, M.M. Frojmovic, E.F. Plow, and M.H. Ginsberg. 1991. Ligand bridging mediates integrin $\alpha \operatorname{IIb} \beta 3$ (platelet GPIIB-IIIA) dependent homotypic and meterotypic cell-cell interactions. $J$. Clin. Invest. 88:1128-1134

52. Spangenberg, P., H. Redlich, I. Bergmann, W. Losche, M. Gotzrath, and B. Kehrel. 1993. The platelet glycoprotein IIb/IIIa complex is involved in the adhesion of activated platelets to leukocytes. Thromb. Haemostasis. 70:514-521.

53. Kuijper, P.H.M., H.I. Gallardo Tores, J.W.J. Lammers, J.J. Sixma, L. Koenderman, and J.J. Zwaginga. 1997. Platelet and fibrin deposition at the damaged vessel wall: Cooperative substrates for neutrophil adhesion under flow conditions. Blood. 89:166-175.

54. Witt, D.P., and A.D. Lander. 1994. Differential binding of chemokines to glycosaminoglycan subpopulations. Curr. Biol. 4:394-400.

55. Lorant, D.E., K.D. Patel, T.M. McIntyre, R.P. McEver, S.M. Prescott, and G.A. Zimmerman. 1991. Coexpression of GMP-140 and PAF by endothelium stimulated by histamine or thrombin: a juxtacrine system for adhesion and activation of neutrophils. J. Cell Biol. 115:223-234.

56. Cooper, D., C.M. Butcher, M.C. Berndt, and M.A. Vadas. 1994. P-selectin interacts with a $\beta_{2}$-integrin to enhance phagocytosis. J. Immunol. 153:31993209.

57. Weyrich, A.S., M.R. Elstad, R.P. McEver, T.M. McIntyre, K.L. Moore, J.H. Morrissey, S.M. Prescott, and G.A. Zimmerman. 1996. Activated platelets signal chemokine synthesis by human monocytes. J. Clin. Invest. 97:1525-1534.

58. Laws, K.H., J.A. Clanton, and V.A. Starnes. 1983. Kinetics and imaging of indium-111-labeled autoogous platelets in experimental myocardial infarction. Circulation. 67:110-116.

59. Ross, R. 1986. The pathogenesis of atherosclerosis-An update. $N$. Engl. J. Med. 314:488-500.

60. Bednar, M.M., S. Raymond, T. McAuliffe, P.A. Lodge, and C.E. Gross. 1991. The role of neutrophils and platelets in a rabbit model of thromboembolic stroke. Stroke. 22:44-50.

61. Del Maschio, A., E. Dejana, and G. Bazzoni. 1993. Bidirectional modulation of platelet and polymorphonuclear leukocyte activities. Ann. Hematol. 67:23-31.

62. Mickelson, J.K., N.M. Lakkis, G. Villarreal-Levy, B.J. Hughes, and C.W. Smith. 1996. Leukocyte activation with platelet adhesion after coronary angioplasty: a mechanism for recurrent disease? J.Am.Coll.Cardiol. 28:345-353. 